\title{
Use of the water-swellable polymers (WSP) for wellbore stabilization in intensely fractured rock intervals
}

\author{
M.I. Sadykov, P.A. Blinov, M.V. Nutskova \\ Saint Petersburg Mining University, Department of Transportation and storage oil and gas, 2, 21st \\ Line, St Petersburg, Russia
}

\begin{abstract}
Current research on the stability of well walls when drilling in fractured rocks and also when drilling inclined sections of the well profile are based on the assessment of the effect of drilling fluid filtrate. The novelty of this work lies in studying the complex effect of a waterswellable polymer on the stability of well wall, on the one hand, and on the controlled loss of circulation on the other. For preparing rock samples, a method was used based on standard laboratory equipment fordrilling fluid properties. The well wall stability tests are performedon a direct shear apparatus.The WSP composition based on alcohol, ether, and surfactant (Polyecanol Flora) showed its efficiency by increasing the stability coefficient with the engagement of less and more internal friction angle.PHPA-based viscoelastic composition showed the best result by increasing the stability coefficient in the hazardous areas by $50-60 \%$.
\end{abstract}

\section{Introduction}

When drilling bores, especially prospecting wells, one of the most frequent types of complications is loss of circulation of drilling fluid, and often a catastrophic loss of circulation with the intensity of more than hundreds of cubic meters of fluid per hour[1]. The second most frequent type of complications is the problem of wellbore wall stability when drilling intervals with a developed rock-fracture zone[2, 3]. As a drilling fluid, the authors $[4,5]$ consider a variety of both water-based and water-free fluids. As a rule, in such works $[6,7]$, the effect of drilling fluid components with binding capacity is evaluated. Authors $[8,9]$ consider water-swellable polymers primarily as water-reducing additives. They investigate properties of solid elastic additives to increase stability and stop loss of drilling mud. Musaab I. Magzouba, Saeed Salehi, Ibnelwaleed A. Hussein, Mustafa S.Nasser, and others [10-11] did not investigate the properties of water-swellable polymers to change the stability of the wellbore after filtration into a fractured interval.

One way of addressing these problems is the creation of insulating compositions based on water-swellable polymers. Water-swellable polymer (WSP) mixtures have a number of advantages over grouting mixtures based on cement with binding component: high degree of filtration into the formation; chemical resistance to aggressive fluids; the speed of operation; high degree of swelling in the first 10-15 hours. 
The work aims to increase the efficiency of drilling directional wells in the intervals of weak and fractured rocks by using drilling fluids with a water-swellable polymer additive in overburden conditions.

\section{Methodology}

Research objectives include:

- $\quad$ Creation of a model of permeable rocks with a certain moisture content; through it;

- Study of a rock sample on a direct shear apparatus after filtration of drilling mud

- Comparative assessment of the effect of different compositions of drilling fluids on the stability of the borehole walls;

- Conclusion on the admissibility and effectiveness of the use of water-swellable polymers to increase the stability of well walls.

Testing of compositions went on permeable rocks with humidity of $18 \%-20 \%$. In the work, 2 models of rock were used:

- The first model was created to analyze the ability of drilling fluid to change the internal friction angle to conclude on the ability to increase the sloped area of the wellbore stability. The first model was made from the medium sand $(0.25 \mathrm{~mm}-0.5 \mathrm{~mm})$;

The second model was created to analyze the ability of the viscoelastic composition to change the internal friction angle and rock binding to conclude that the stability of the rock-fractured wellbore zone stability increases. The second model was made from the mixture of hard grained sandy rocks $(1 \mathrm{~mm}-2 \mathrm{~mm})$ and small gravel fractions $(2 \mathrm{~mm}-4 \mathrm{~mm})$ in the ratio of 1 to 1 .

Then the rock model No. 1 was put in the filter press and through it, the drilling fluid is filtered for half an hour at apressure drop of $0.7 \mathrm{MPa}$. The model of the rock formation No. 2 was also put into the filter press, where $t$ the visco-elastic composition of WSP is filtered through if for one hour at a pressure drop of $1 \mathrm{MPa}$.

The following structures of drilling fluid were used:

1st structure: water + chalk $\left(\mathrm{CaCO}_{3}\right) 50 \mu \mathrm{m}$ (water $1 \mathrm{~kg}$, chalk $0.15 \mathrm{~kg}$; total volume 1 liter) liter)

2nd structure: water + liquid glass $5 \%$ (water $1 \mathrm{~kg}$, liquid glass $0.05 \mathrm{~kg}$; total volume 1

3rd structure: water + liquid rubber $5 \%$ (water $1 \mathrm{~kg}$, liquid rubber $0.05 \mathrm{~kg}$; total volume 1 liter)

4th structure: water + chalk $\left(\mathrm{CaCO}_{3}\right)+$ Comet-Meteor (KM-PVR) 3\% (water $1 \mathrm{~kg}$, chalk $0.15 \mathrm{~kg}$, Comet-Meteor (KM-PVR) $0.03 \mathrm{~kg}$; total volume 1 liter)

5 th structure: water + xanthan gum $5 \%$ (water $1 \mathrm{~kg}$, xanthan gum $0.05 \mathrm{~kg}$; total volume 1 liter)

The used structures of a water-swellable polymers composition:

1st structure: water + WSP 5\% (water $1 \mathrm{~kg}$, WSP $0.05 \mathrm{~kg}$; total volume 1 liter)

2nd structure: Polyakonol-Flora + WSP 5\% (Polyakonol-Flora $1 \mathrm{~kg}$, WSP $0.05 \mathrm{~kg}$; total volume 1 liter)

3rd structure: water + PHPA 5\% (water $1 \mathrm{~kg}$, PHPA $0.05 \mathrm{~kg}$; total volume 1 liter)

\section{Results and discussion}

Before feeding viscoelastic compositions to the bottom, it is necessary to lift the device to a distance of $0.3-0.5$ meter from the bottom. After delivering the compositionto the bottom, it is necessary to wait 4-5 hours for the WSP to open enough to bind the rocks. One of the 
advantages of using WSP is its versatility regardless of the fracture type (horizontal or vertical). Activation of the composition takes 45-50 minutes from the moment the WSP enters the water. The composition is easy to drill, i.e., after 4-6 hours from the moment the composition is fed to the bottom, the drilling continues without the necessity of the AT changing.

Table 1. The results of drilling fluids filtration testing.

\begin{tabular}{|c|c|c|c|c|c|c|}
\hline Sample & $\begin{array}{l}\text { A control } \\
\text { sample of the } \\
\text { rock } \\
\text { (moisture } \\
18 \%-20 \%)\end{array}$ & $\begin{array}{l}\text { Water }+ \\
\text { CaCo3 } \\
(50 \mu \mathrm{m})\end{array}$ & $\begin{array}{l}\text { Water }+5 \% \\
\text { liquid glass }\end{array}$ & $\begin{array}{l}\text { Water }+5 \% \\
\text { liquid rubber }\end{array}$ & $\begin{array}{c}\text { Water }+ \\
\text { CaCo3 } \\
(50 \mu \mathrm{m})+ \\
\text { KM-PVR } \\
3 \%\end{array}$ & $\begin{array}{l}\text { Water + } \\
\text { xanthan } \\
\text { gum } 5 \%\end{array}$ \\
\hline $\mathrm{C}^{*}, \mathrm{kPa}$ & 27.43 & 15.9 & 14.47 & 24.19 & 14.01 & 31 \\
\hline $\begin{array}{c}\rho^{*}, \\
\text { degree }\end{array}$ & 27.57 & 30.22 & 32.93 & 27.45 & 33.58 & 39.7 \\
\hline $\begin{array}{l}\text { Zenith } \\
\text { angle } \theta\end{array}$ & $\mathrm{n}^{*}$ & $\mathrm{n}^{*}$ & $\mathrm{n}^{*}$ & $\mathrm{n}^{*}$ & $\mathrm{n}^{*}$ & $\mathrm{n}^{*}$ \\
\hline $15^{\circ}$ & 4.104 & 4.669 & 5.314 & 4.08 & 5.48 & 7.328 \\
\hline $30^{\circ}$ & 1.993 & 2.253 & 2.548 & 1.982 & 2.624 & 3.461 \\
\hline $45^{\circ}$ & 1.33 & 1.494 & 1.679 & 1.322 & 1.726 & 2.245 \\
\hline $60^{\circ}$ & 1.035 & 1.158 & 1.294 & 1.03 & 1.329 & 1.707 \\
\hline $75^{\circ}$ & 0.90 & 1.003 & 1.117 & 0.896 & 1.146 & 1.459 \\
\hline $90^{\circ}$ & 0.86 & 0.957 & 1.064 & 0.856 & 1.092 & 1.386 \\
\hline
\end{tabular}

Table 2.The results of viscoelastic compositions filtration testing.

\begin{tabular}{cccccc}
\hline Sample & $\begin{array}{c}\text { A control } \\
\text { sample of the } \\
\text { rock (moisture } \\
18 \%-20 \%)\end{array}$ & $\begin{array}{c}\text { Water + WSP } \\
5 \%\end{array}$ & $\begin{array}{c}\text { Polyakonol- } \\
\text { Flora + WSP } \\
5 \%\end{array}$ & $\begin{array}{c}\text { Water + 5\% } \\
\text { WSP (12-hour } \\
\text { settling in } \\
\text { desiccator) }\end{array}$ & $\begin{array}{c}\text { Water + } \\
\text { PHPA 5\% }\end{array}$ \\
\hline $\begin{array}{c}\mathrm{C}^{*}, \mathrm{kPa} \\
\rho^{*},\end{array}$ & 4 & 11 & 3 & 14 & 3 \\
degree & 27 & 26 & 30 & 31 & 38 \\
$\begin{array}{c}\text { Zenith } \\
\text { angle } \theta\end{array}$ & $\mathrm{n}^{*}$ & $\mathrm{n}^{*}$ & $\mathrm{n} *$ & $\mathrm{n}^{*}$ & $\mathrm{n}^{*}$ \\
$15^{\circ}$ & 4.031 & 3.794 & 4.62 & 4.847 & 6.756 \\
$30^{\circ}$ & 1.959 & 1.849 & 2.231 & 2.335 & 3.203 \\
$45^{\circ}$ & 1.308 & 1.238 & 1.48 & 1.545 & 2.086 \\
$60^{\circ}$ & 1.019 & 0.967 & 1.147 & 1.196 & 1.591 \\
$75^{\circ}$ & 0.887 & 0.842 & 0.994 & 1.035 & 1.364 \\
$90^{\circ}$ & 0.847 & 0.806 & 0.949 & 0.987 & 1.296 \\
\hline
\end{tabular}

${ }^{*} \mathrm{C}$ - Soil adhesion $(\mathrm{KPa}), \mathrm{p}$ - angle of shearing resistance $\left({ }^{\circ}\right), \mathrm{n}$ - well wall stability coefficient.

The zenith angle $(\theta)$ is the angle between the borehole axis or tangent to it and the vertical. Soil adhesion $(C)$ is a value that determines the strength of the structural bonds of the rock through stress. The angle of shearing resistance $(p)$ is the proportionality factor between normal and shear stresses. The well wall stability coefficient (n) is the proportionality coefficient between the ultimate strength of the rock and the maximum shear stress in the borehole wall.

The first application the composition had at the Sibay pyrite poly-metallic ore deposit. The drilling was held on the open-pit side, which was developed by anexplosive method. The projected depth of the core-drilling is 600 meters, the diameter is NQ. From a depth of 155 meters, according to a well drilling program, a zone of intensely fractured rock with the 
developed areas of horizontal and vertical fractures is spread. Thus, when drillingthe $155 \mathrm{~m}$ - $305 \mathrm{~m}$ interval (multiclastic tuff withpredominantly basalt composition, medium to intensely (up to 1 meter) fractured), drilling was stoppeddue to permanent collapse of the borehole wall and catastrophic loss of circulation. Given the current problems, the drilling contractor decided to use viscoelastic compositions. To do this, the viscoelastic WSPcomposition in the concentration of 5\% was injected through the drill rod strung without core recovery tube, and then injected with water and left under the static level of drilling fluidpressure. Then, after 6 hours, the composition was drilled and the core was taken from the demountable core recovery tube.

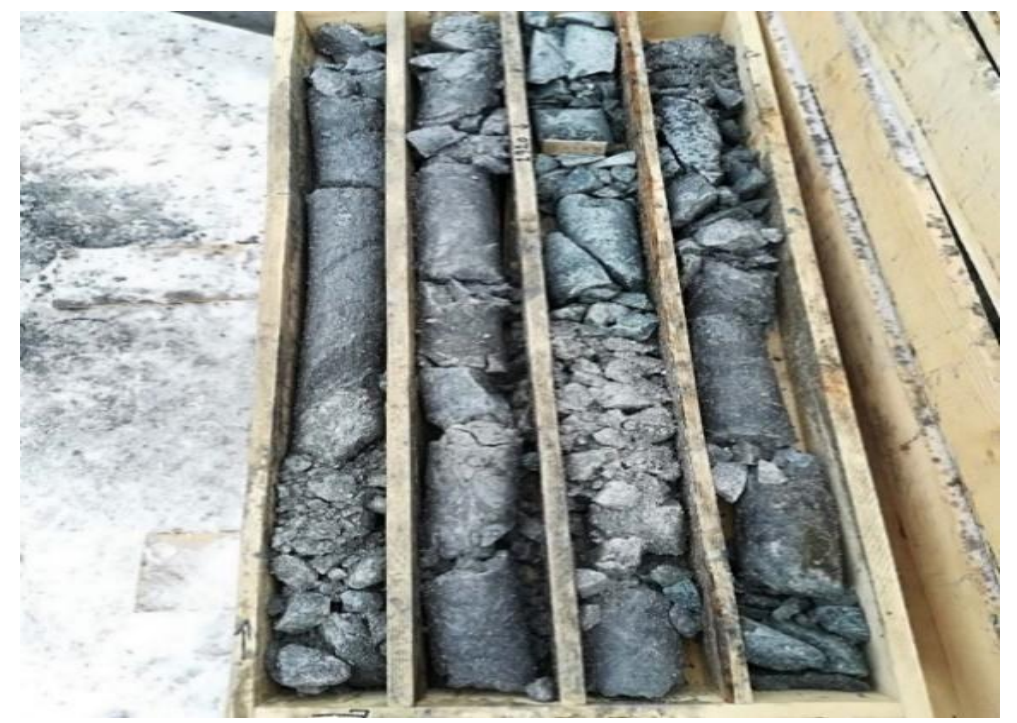

Fig. 1. A core of unstable fractured rocks from the Sibay deposit.

\section{Conclusion}

While investigating drilling fluids, the best results in the stabilization of well walls were shown by the drilling fluid based on water and xanthan gum. Xanthan gum increases both rock engagement and the angle of internal friction, which positively affects the stability of the borehole wall.

Water-based WSP composition with a short opening time increases rock engagement but lowers the angle of internal friction. With a 12-hour exposure of the composition, both the engagement and the angle of internal friction angle increase, what enables to make a statement about an increase in the stability coefficient.

The WSP composition based on alcohol, ether, and surfactants (Polyecanol Flora) has shown its efficiency by increasing the stability coefficient with less engagement and an increase in the angle of internal friction.

The visco-elastic composition based on PHPA showed the best result by increasing the stability coefficient in hazardous areas by $50-60 \%$; however, PHPA is a water-soluble compound and with a strong water- contact compound will dissolve the strength characteristics of the wellbore walls, increasing the likelihood of wellbore wall collapse. This composition is recommended for use with subsequent conversion to waterless drilling fluids. 


\section{References}

1. M.D. Zoback, Reservoir Geomechanics. (UK, Cambridge: Cambridge University Press, 2007).

2. E.V. Babayan, Construction of oil and gas wells. Complications and their overcoming: Textbook. (Vologda: Infra-Engineering,2018).

3. A.V. Korenyako, N.A.Petrov, I.N.Davydova, S.F. Komleva Investigation of a waterswelling polymer in order to expand the area of application of the reagent. [Electronic resource]. Oil and gas business, 1, 1-17 (2007).

4. E.L. Leusheva, V.A. Morenov, Effect of carbonate additives on dynamic filtration index of drilling mud.International Journal of Engineering, Transactions B: Applications. 5(33): 934 - 939(2020).

5. P.A. Blinov, Determining the Stability of the Borehole Walls at Drilling Intervals ofLoosely Coupled Rocks Considering Zenith Angle. Journal of Mining Institute. 236: 172-179(2019).

6. S.S. Tabatabaee, N.I. Nikolaev, Assessment of Uncertainties in Wellbore Stability Analysis.SN Applied Sciences. 2(3): 437-437(2020).

7. S.S. TabatabaeeMoradi, N.I.Nikolaev, S.A. Khormali, Comprehensive uncertainty assessment of wellbore stability model.Saint Petersburg: Innovations in Geosciences. 65533 (4429): 327 - 342(2018).

8. I.V. Chudinova, N.I. Nikolaev, Development of the composition and study of the properties of drilling mud for drilling wells in unstable clay rocks.Successes of modern natural science. 8: 85 - 89(2019).

9. Hanyi Zhonga, Guangcheng Shena, Zhengsong Qiua, YongxueLinb, LijunFanaXiaodongXingc, Jia Lia. Minimizing the HTHP filtration loss of oil-based drilling fluid with swellable polymer microspheres. Journal of Petroleum Science and Engineering.172: 411-424 (2019).

10. Ma Lan, Luo Pingya, HeYi, ZhangLiyun, FanYi, JiangZhenju. Improving the stability of multi-walled carbon nanotubes in extremely environments: Applications as nanoplugging additives in drilling fluids. Journal of Natural Gas Science and Engineering Volume.74, 103082 (2020).

11. T.Liu, E.L.Leusheva, V.A. Li, L.Morenov, G. Jiang, Influence of polymer reagents in the drilling fluids on the efficiency of deviated and horizontal wells drilling.Energies. 18(13): 1-16(2020).

12. V.S.Litvinenko, M.V. Dvoynikov, Methodology for determining the parameters of drilling mode for directional straight sections of well using screw downhole motors.Journal of Mining Institute. 241: 105-112(2020).

13. Xu Yang, Xiangchao Shi, YingfengMeng, Xiaoyong Xie, Wellbore stability analysis of layered shale based on the modified Mogi-Coulomb criterion.Petroleum.6(3): 246252(2020). 